\title{
Erratum to: Is Prophylactic Intervention More Cost-effective Than the Treatment of Pathologic Fractures in Metastatic Bone Disease?
}

\author{
Alan T. Blank MD, MS, Daniel M. Lerman MD, \\ Neeraj M. Patel MD, MPH, Timothy B. Rapp MD
}

Published online: 25 April 2016

(C) The Association of Bone and Joint Surgeons( 2016

\section{Erratum to: Clin Orthop Relat Res \\ DOI 10.1007/s11999-016-4739-x}

In the study, "Is Prophylactic Intervention More Cost-effective Than the Treatment of Pathologic Fractures in Metastatic Bone Disease?" two of the tables were published in the wrong order.

Table 2 should be:

Table 2. Comparison of variables by presence of pathologic fracture

\begin{tabular}{llll}
\hline Variable & Pathologic fracture & No fracture & p value \\
\hline Implant cost & $47 \pm 25 \mathrm{CU}$ & $54 \pm 26 \mathrm{CU}$ & 0.38 \\
Direct cost & $382 \pm 300 \mathrm{CU}$ & $227 \pm 93 \mathrm{CU}$ & 0.038 \\
Total cost & $642 \pm 519 \mathrm{CU}$ & $370 \pm 171 \mathrm{CU}$ & 0.036 \\
Length of stay & $8 \pm 6$ days & $4 \pm 3$ days & \\
Disposition & & & \\
Home & $12(57 \%)$ & $16(84 \%)$ & 0.01 \\
Rehabilitation facility & $8(38 \%)$ & $2(11 \%)$ & $1(5 \%)$ \\
Hospice & $1(5 \%)$ &
\end{tabular}

$\mathrm{CU}=$ cost unit.

The online version of the original article can be found under doi:10.1007/s11999-016-4739-x.

A. T. Blank ( $₫)$, N. M. Patel, T. B. Rapp

NYU Hospital for Joint Diseases, 301 E. 17th Street, New York,

NY 10003, USA

e-mail: alan.blank@nyumc.org

D. M. Lerman

Department of Orthopaedics, University of Maryland School of

Medicine, Baltimore, MD, USA 
Table 3 should be:

Table 3. Analysis of patients with lower extremity disorders

\begin{tabular}{llll}
\hline Variable & Pathologic fracture & No fracture & $p$ value \\
\hline Implant cost & $55 \pm 27 \mathrm{CU}$ & $52 \pm 24 \mathrm{CU}$ & 0.72 \\
Direct cost & $374 \pm 272 \mathrm{CU}$ & $237 \pm 92 \mathrm{CU}$ & 0.06 \\
Total cost & $634 \pm 477 \mathrm{CU}$ & $390 \pm 169 \mathrm{CU}$ & 0.059 \\
Length of stay & $7 \pm 6$ days & $4 \pm 3$ days & \\
Disposition & & & $14(82 \%)$ \\
Home & $8(62 \%)$ & $2(12 \%)$ & 0.053 \\
Rehabilitation facility & $4(31 \%)$ & $1(6 \%)$ \\
Hospice & $1(8 \%)$ & & 0.2 \\
\hline
\end{tabular}

$\mathrm{CU}=$ cost unit.

Additionally, in Table 2, the average hospital length of stay for all patients with pathologic fractures was incorrectly published as $7 \pm 6$ days with a $p$ value of 0.053 . The average hospital length of stay for all patients with pathological fractures should be $8 \pm 6$ days with a $\mathrm{p}$ value of 0.01 . Table 2 above reflects these changes.

The authors apologize for the errors. 